\title{
EL PENSAMIENTO HUMANO Y SUS MATERIALIZACIONES
}

\author{
Human Thought And its Materializations
}

\author{
Martin Lienhard* \\ DOI: http://dx.doi.org/10.29043/liminar.v19i2.839
}

\begin{abstract}
Resumen: El presente artículo intenta una mirada distante de aquellas tradiciones que estudian la oralidad y de las sociedades que no conocen la escritura privilegiando la producción-recepción de discursos verbales. El punto de partida es que ese tipo de sociedades disponen, si nos referimos a su tecnología comunicativa, no de uno, sino de dos sistemas de comunicación verbal: el oral (o vocal) y el gestual. El sistema gestual, como el moderno lenguaje gestual destinado a los sordos, traduce, como la escritura, un discurso verbal; es por lo tanto -igual que los subtítulos en el cine-, una especie de escritura efímera. El uso de uno o de otro de los dos sistemas depende del contexto: la escritura gestual se usa en público y la oralidad vocal en la esfera íntima. En términos

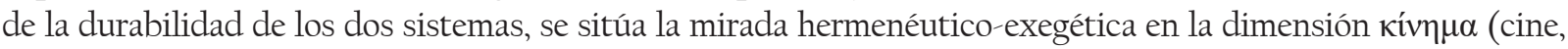
movimiento), recorriendo y recurriendo a poemas orales, mitos y mitografías, pinturas primordiales y lienzos precolombinos, además del diálogo con especialistas en la materia.
\end{abstract}

Palabras clave: oralidad, escritura, culturas, mitos, modernidad.

Abstract: This article endeavors to contemplate from afar traditions that study orality and of societies that do not have a writing system, thus privileging the production-reception of verbal discourses. The starting premise is that such societies have, if we refer to their communicative technology, not one but two systems of verbal communication: the oral (or vocal) and the gestural. The gestural system, like the modern gestural language for the deaf, translates, like writing, a verbal discourse; it is therefore, like subtitles in the cinema, a kind of ephemeral writing. The use of one or the other of the two systems depends on the context: Gestural writing is used in public and vocal orality in the intimate sphere. In terms of the durability of the two systems, the hermeneutic-exegetical gaze is placed in the кív $\mu \alpha$ dimension (film, movement), traversing and drawing on oral poems, myths, and mythographies, primordial paintings, and pre-Columbian canvases, in addition to dialogue with specialists in the field.

Key words: orality, writing, cultures, myths, modernity.

\footnotetext{
* Martin Lienhard. Doctor en Letras por la Universidad de Ginebra, Suiza. Profesor emérito de la Universidad de Zúrich, Suiza; profesor en la Universidad Nacional de Jujuy (UNJU), Argentina; profesor en la Pontificia Universidad Católica del Perú (PUCP), Perú; profesor en la Universidad Andina Simón Bolívar, Ecuador; profesor en la Universidad Nacional Mayor de San Marcos, Perú. Temas de especialización: estudios latinoamericanos y africanos. Correo electrónico: lienhard@ rom.uzh.ch. ORCID: https://orcid.org/0000-0003-0932-6456
}

Enviado a dictamen: 1 de octubre de 2020

Aprobación: 1 de diciembre de 2020 
Perché abbiamo l'abitudine di chiamare solo « orali » le tradizioni dei popoli che non conoscono l'uso della scrittura? (iPor qué solemos calificar solo de "orales" las tradiciones de los pueblos que no conocen el uso de la escritura?) Carlo Severi, Il percorso e la voce (2004).

\section{Introito}

$\square$ n su carnavalesco diario de un viaje a la Amazonía en el año 1927, recogido en O turista aprendiz, el famoso poeta, novelista y musicólogo paulista Mário de Andrade narra su encuentro con los pacaás novos, una tribu indígena - dice- "bastante curiosa por sus usos y costumbres" (Andrade, 1983). Según el autor, en efecto, los indios en cuestión se prohíben exhibir en público su cabeza y todas las prácticas relacionadas con la boca y las orejas, mientras que las que suponen la participación de las demás partes del cuerpo, entre ellas los genitales, las exponen a la vista de todos. Cuando se encuentran en un espacio público, los pacaás novos llevan, amarrada al cuello, una especie de minifalda al revés que les cubre la cabeza. Según el etnógrafo, los indios:

Consideran la nariz y las orejas como las partes más vergonzosas del cuerpo, partes que no se muestran a nadie, ni siquiera a los padres, solo al marido o a la mujer en la más rigurosa intimidad. Escuchar, para ellos, es lo que nosotros llamamos un pecado mortal. Hablar es el máximo de la sensualidad. Si los actos de procreación se dan en cualquier lugar, hora y presencia ajena, esto no sucede muy frecuentemente por el deber que tienen de esconder los gestos excitatorios del amor, que provienen exclusivamente de la fonación (Andrade, 1983:92). ${ }^{2}$

La virginidad, para los pacaás novos, es la del oído. Cuando una pareja decide casarse,

el novio llega a la casa del padre de la pequeña y dice que viene a pedir su voz; lo dice, obviamente, hablando con los pies [...]. Si el padre accede a su pedido, después de un bacororô [nombre de una danza indígena], la nueva pareja, en silencio y con mucha cosa muy fea para nosotros, se va a su casa $y$, cerradas las puertas, inician un diálogo que no termina nunca (Andrade, 1983:92).

Cuando necesitan hablar en público, los pacaás novos lo hacen con los pies, "moviendo los deditos de los mismos con una habilidad prodigiosa de desenvoltura" (Andrade, 1983).

Los pacaás novos inventados por Mário de Andrade representan lo que Walter Ong o Paul Zumthor llamarían sin duda una sociedad de "oralidad primaria", una sociedad que no conoce la escritura. Pero ellos disponen, si nos referimos a su tecnología comunicativa, no de uno, sino de dos sistemas de comunicación verbal: el oral (o vocal) y el gestual. El sistema gestual, como el moderno lenguaje gestual destinado a los sordos, traduce, como la escritura, un discurso verbal; es, por lo tanto -igual que los subtítulos en el cine-, una especie de escritura efimera. El uso de uno u otro de los dos sistemas depende del contexto: la escritura gestual se usa en público, la oralidad vocal en la esfera íntima.

Los estudios sobre la oralidad suelen privilegiar -o incluso limitarse a - la producción-recepción de discursos verbales. Es probable que esta inclinación casi exclusiva hacia lo verbal tenga que ver con el hecho de que estos estudios, históricamente, se hayan originado en el análisis de textos orales transcritos, en particular las epopeyas homéricas y los mitos de pueblos "sin escritura" o "de tradición oral". Por eso mismo, la temática predominante en los estudios sobre la oralidad suele ser la relación entre el discurso verbal oral y el discurso verbal escrito o transcrito. Para algunos autores, esta relación es básicamente de tipo ancilar. Para Saussure, por ejemplo, la escritura sirve ante todo para fijar el discurso oral en un soporte duradero. Para otros, la escritura no es solo una tecnología nueva para la comunicación verbal, sino una práctica que inaugura o implica otro modo de pensar. Así lo formuló, un siglo y medio antes del Cours de linguistique générale de Saussure, su compatriota Jean-Jacques Rousseau: 
La escritura, aparentemente destinada a fijar la lengua, es precisamente lo que la altera; no modifica sus palabras, pero su genio, sustituyendo la exactitud a la expresión. Cuando hablamos traducimos nuestros sentimientos; cuando escribimos, nuestras ideas. Al escribir estamos obligados a usar las palabras en su acepción común; pero aquel que habla varía las acepciones por los tonos, las determina como quiere; menos preocupado por la claridad da más importancia a la fuerza [...] (Rousseau, [1782]2012:355). ${ }^{3}$

Esto es lo que Rousseau dice acerca de las diferencias entre lengua hablada y escritura. Pero cumpliendo con lo que promete el título de su tratado, Essai sur l'origine des langues (Ensayo sobre el origen de las lenguas), se interroga sobre los comienzos de la comunicación entre los seres humanos. Y al principio está, afirma el filósofo ginebrino, el lenguaje gestual. "Si nunca hubiéramos tenido otras necesidades que físicas, dice, hubiéramos muy bien podido no hablar nunca y entendernos perfectamente mediante la lengua del gesto" (Rousseau, [1782]2012:361). ${ }^{4}$ Son las necesidades morales y las pasiones las que hicieron nacer, según Rousseau, el lenguaje verbal, pero sin que desapareciera el lenguaje gestual:

Los medios generales que nos permiten impactar en los sentidos de otros no son sino dos: el movimiento y la voz. La acción del movimiento es inmediata por el tacto o mediata por el gesto: la primera, limitada por el tamaño del brazo, no puede transmitirse a distancia: pero la otra alcanza todo el radio visual. Así solo quedan la vista y el oído como órganos pasivos del lenguaje entre hombres dispersos.

Aunque ambas, la lengua del gesto y la de la voz, sean naturales, la primera es más fácil y depende menos de las convenciones: más objetos impactan en los ojos que en el oído y las figuras ostentan más variedad que los sonidos, son también más expresivas y dicen más en menos tiempo (Rousseau, [1782]2012:358). ${ }^{5}$

El oído capta la voz, la vista capta el gesto. Pero hay un tercer sentido involucrado en la comunicación interpersonal cercana: el tacto. En otro pasaje, Rousseau, citando al orientalista Jean Chardin, refiere que en la India: “[...] los factores, ${ }^{6}$ tomándose uno la mano del otro y modificando sus toques de manera que a nadie le llame la atención, tratan públicamente, pero en secreto, todos los negocios sin pronunciar palabra alguna" (Rousseau, [1782]2012:362). ${ }^{7}$

\section{El pensamiento teatralizado}

En 1956, el historiador Lewis Mumford, en Las transformaciones del hombre, esbozó una posible historia del ser humano que él mismo calificó, algo irónicamente, de "mito de origen". En su manera de enfrentarse con el mundo, explica, el hombre se deja guiar por el deseo. El deseo, puntualiza, "no es solo el padre del pensamiento: es la fuente de todos los actos y de todos los comportamientos creativos del hombre" (Mumford, [1956]2008:28)
Nacido en un mundo de sensaciones y de pulsiones motrices, el hombre maduró en un mundo de signi- ficados y de valores. En realidad, su cultura se basa ante todo en su aptitud para convertir los materiales brutos de la existencia en formas que mueven por ellas mismas la vida social y favorecen el desarrollo del individuo. Así, el hombre no vive sencillamente su vida al día de manera sobria y prosaica: la teatraliza y la interpreta a la manera de un actor (Mumford, [1956]2008:32).

Como los animales, el hombre nació en un mundo de sensaciones y pulsaciones, pero, a diferencia de sus primos, no se contentó con una existencia más o menos vegetativa o rutinaria, sino que reflexionó sobre lo que había sido, era o podía llegar a ser y sobre lo que había hecho, hacía o anhelaba hacer. El hombre no se contenta, por ejemplo, con cazar animales o sembrar algún alimento, sino que transforma esos actos prácticos en actos de segundo grado, en meta-actos, si se me permite este neologismo; en actos rituales o ritualizados que constituyen un discurso simbólico sobre el mundo y el hombre. O, como lo expresa Mumford: "El hombre se hace hombre formalizando, ritualizando, simboli- 
zando, teatralizando toda acción natural que realiza" ([1956]2008:33). Lo que precede queda ilustrado, por ejemplo, por la manera como los indios pawnee estudiados por Alice Cunningham Fletcher ritualizaban la travesía de una corriente de agua, invocando en cada etapa a uno de los avatares de Tirawa, el espíritu supremo. ${ }^{8}$ André Leroi-Gourhan, uno de los grandes estudiosos de la prehistoria del hombre, explica cómo nace el pensamiento "simbólico":

[...] la tecnicidad bipolar de numerosos invertebrados desembocó entre los antrópidos en la formación de dos parejas funcionales (mano-herramienta y rostrolenguaje), haciendo intervenir en primer lugar la motricidad de la mano y del rostro en el modelado del pensamiento en tanto instrumentos de acción material y en tanto símbolos sonoros. La emergencia del símbolo gráfico al finalizar el reino de los paleanthropos supone el establecimiento de relaciones nuevas entre los dos polos operativos, relaciones exclusivamente características de la humanidad en el sentido estrecho del término, respondiendo a un pensamiento simbolizador, en la misma medida en que nosotros mismos nos servimos de él (LeroiGourhan, 1964:262). ${ }^{9}$

En otras palabras, en el paleolítico, el hombre comienza encargando la expresión de su pensamiento a su mano - ya innecesaria para su locomoción- y a su voz. El "pensamiento manual" que se manifiesta en sus actividades productivas se coordina con la fonación y viceversa. Esto se aprecia todavía, ya en plena época del bronce, en la construcción de un puente colgante sobre el río Apurímac tal como la describe, a mediados del siglo XVI, el cronista Juan de Betanzos en su Suma y narración de los incas; quien lleva la "voz cantante" es el inca Pachacuti Ynga Yupangue:

E llegado que fue al río de Aporima, que es diez leguas de la ciudad del Cuzco, hizo hacer unos estribos y entradas de puente, en los cuales puso ciertos travesaños de piedras largas e maderos gruesos; e luego hizo hacer unas crisnejas de unas baras que casi quieren paresçer a baras de membrillos, las cuales baras son ansí delgadas y recias, de las cuales hizo hacer unas crisnejas de largor de la anchura del río tanto y medio,

la crisneja de las cuales de un palmo largo de anchor e de seis dedos de altura e gordor,

de las cuales hizo hacer catorce crisnejas.

De las siete de las cuales hizo hacer puente en esta manera:

que los estribos de la puente y entrada della es tan ancha como seis pies y de altor un estado

y luego al entrar della está hecho cierto hoyo grande, en el cual hoyo están los travesaños que toman de parte a parte y son dos y tres;

y al primero junto a la puerta con el un cavo de la una crisneja hizo dar una vuelta al tal estribo

y de allí con la resta del mismo cabo hizo dar otra vuelta y luego en el postrer estribo y trabesaño hizo dar otra vuelta postrera

(Betanzos, 2015:202-203; disposición gráfica propia).

La compleja ingeniería del puente colgante sobre el río Apurímac supone no solo una gran habilidad manual, sino también un pensamiento sofisticado y nutrido por una experiencia sin duda muy larga. Al dirigir los trabajos, con su voz, el propio inca demuestra ser el depositario máximo de la sabiduría manual que permite imaginar y luego realizar este tipo de puentes. ${ }^{10}$

\section{Primeros grafismos}

Al final del paleolítico aparece el símbolo gráfico. En su propio "mito de origen", Leroi-Gourhan imagina el origen del pensamiento gráfico:
Al pisoteo que constituye el marco rítmico de la mar- cha se agrega [...] en el hombre la animación rítmica del brazo; el primero patrocina la integración espacio- temporal y está a la base de la animación en el dominio social, mientras que el movimiento rítmico del brazo abre otra salida, la de la integración del individuo en un dispositivo creativo ya no espacial ni temporal, 
sino de formas. La ritmicidad del paso ha desembocado en el kilómetro y en la hora, la ritmicidad manual ha llevado a la captura y la inmovilización de los volúmenes, fuente de una reanimación puramente humana (Leroi-Gourhan, 1965:136)."

Los ejemplos más antiguos de simbolismo gráfico son las incisiones a distancias más o menos regulares que se encuentran en pequeños objetos alargados sobre cuya función exacta solo se puede especular (ver Figura 1). Leroi-Gourhan los comparó con los churingas de los aborígenes australianos:

\section{[...] el churinga, dice el famoso historiador, concretiza} la recitación de encantamiento, es su soporte y el oficiante, con la punta del dedo, sigue las figuras según el ritmo de su declamación. Así, el churinga moviliza las dos fuentes de la expresión, la de la motricidad verbal, ritmada, y la de un grafismo que participa en el mismo proceso dinámico (Leroi-Gourhan, 1964:263).

En realidad, como lo muestra un trabajo de Monika Moisseeff (1988-1989), el churinga moviliza otra fuente de expresión más, el movimiento humano en el espacio. Lo que se "lee" en esos objetos, en efecto, es la peregrinación sobre la faz de la tierra de un "ser del sueño", un ancestro mítico; esta peregrinación mítica se materializa en el ritual que se le dedica. El churinga representa una parcela del territorio atravesado por ese personaje mítico, y los signos gráficos inscritos en su superficie representan sus huellas.

A diferencia de la escritura propiamente dicha, el grafismo es una práctica que existe desde el paleolítico tardío en todas las sociedades humanas conocidas. Desde hace tres o cuatro decenas de miles de años, ${ }^{12} \mathrm{el}$ grafismo acompaña el lenguaje verbal, sea el lenguaje verbal rítmico tal como se presenta en los momentos rituales o aquel que se usa para la narración de mitos. "Mitología y grafismo multidimensional — dice LeroiGourhan - son normalmente coincidentes en las sociedades primitivas y si osara usar el contenido estricto de las palabras, estaría tentado de equilibrar la 'mito-logía', construcción multidimensional basada en lo verbal, con una 'mitografía' que sería su estricto equivalente manual" (Leroi-Gourhan, 1964:272).

Si bien carecen de una escritura directamente vinculada - o subordinada - al lenguaje verbal, las sociedades "de tradición oral" no dejan, pues, de hacer uso de sistemas gráficos coordinados, de una u otra manera, con el lenguaje verbal. Todas las sociedades humanas, como ya lo dijo Rousseau ([1782]2012), disponen también, desde siempre, de otro sistema más de comunicación: la "lengua del gesto". No hay sociedad, por otro lado, que ignore la danza, lenguaje que podemos derivar de la lengua del gesto y del pisoteo rítmico mencionado por Leroi-Gourhan, un movimiento que rige, como dice el historiador, "la integración espacio-temporal y está a la base de la animación en el dominio social". Podríamos, además, referirnos a otros lenguajes, como el de la música vocal, que se origina, si seguimos a Rousseau, en el lenguaje verbal; o a los lenguajes percusivos practicados en África, Asia y la América originaria. Los cuatro lenguajes apenas mencionados, el del gesto, el de la música vocal, el de la percusión rítmica y el de la danza, se hallan a menudo asociados en las prácticas rituales, frecuentemente vinculadas, a su vez, con narrativas míticas. Hablando de la "expresión literaria primitiva”, el gran antropólogo Franz Boas (1955:303) alude a la "asociación frecuente de canto y danza, de canto y juego, de gestos y habla animada". ${ }^{13}$ Tomando en cuenta todo lo que precede, se hace evidente que si definimos como meramente "orales" o "de tradición oral" a las sociedades que no conocen o no desarrollaron una escritura ligada a la fonación estamos reduciendo enormemente la verdadera amplitud y riqueza de sus prácticas comunicativas. Pretendo explorar, a continuación, algunos aspectos de la "más-que-oralidad" que caracteriza el plurisistema comunicativo de las sociedades arcaicas.

\section{Mitografías}

En sus viajes por las regiones equinocciales del nuevo continente, Alexander von Humboldt tuvo la oportunidad de ver, en la Venezuela orinoquense, varios petroglifos. Vale la pena citar su comentario: 
Nos han mostrado aún, cerca del peñasco de Culimacari, sobre las orillas del Casiquiare, y en el puerto de Caicara en el Bajo Orinoco, unos signos que se creen caracteres alineados. Con todo no eran sino unas figuras informes representando los cuerpos celestes, tigres, cocodrilos, boas e instrumentos que servían para la fabricación de la harina de yuca. Era imposible reconocer en estas rocas pintadas (es la designación con la cual los indígenas señalan esas masas cargadas de figuras) un arreglo simétrico, unos caracteres regularmente espaciados. Las figuras descubiertas en las montañas de Uruana, por el misionero Fray Ramón Bueno, se acercan más a una escritura simbólica: con todo, esos mismos caracteres [...] dejan todavía muchas dudas (Humboldt, 1991:IV, 402-403).

Los informantes tamanacos de Humboldt relacionan esas figuras con lo que el viajero alemán califica de "mitología local". Según esta narrativa, el mar, penetrando en el interior del continente, acabó con todos los hombres. Amalivaca, el ancestro mítico de los tamanacos, logró, bogando en su embarcación, grabar en la "roca pintada" (tepumereme) las figuras de la luna y el sol (Humboldt, 1991:IV, 403-404). Ese mito local no es, sin embargo, la tradición oral que permitiría "leer" las incisiones rupestres, sino una narrativa mítica posterior, tamanaca, que pretende explicar su origen. En cuanto al mito aludido por las figuras del petroglifo, Humboldt, negándose con razón a atribuir a los petroglifos la calidad de "escritura", no intenta imaginar su sentido. Sus creadores, anteriores a los tamanacos contemporáneos de Humboldt, pretendían sin duda aludir al cielo, a sus ancestros míticos (los animales más poderosos) y su alimento básico: la mandioca.

La pareja fonación-grafismo postulada por LeroiGourhan puede ser de muy diversa naturaleza. Lo veremos en el ejemplo siguiente. Los quiocos o chokwe, una gran población bantú del interior de Angola (Lundas) "pasan horas ilustrando sus conversaciones con dibujos en el suelo, relacionados con leyendas, animales, adivinanzas, símbolos y juegos". Mário Fontinha, autor de un libro sobre tales dibujos, comenta que ese pasatiempo es "una curiosa forma de comunicar con la comunidad recordando hechos y tiempos pasados" (Fontinha, 1983:37). Estamos, por lo tanto, ante un grafismo vinculado con un universo básicamente mítico. Los dibujos, llamados en chokwe lusona (singular) y sona (plural), son signos convencionales que no solo los chokwes, sino también otras poblaciones de la región, interpretan de la misma manera. Explica este autor: "El patrón debe ser obedecido de modo riguroso, sencillamente porque está consagrado y a veces ritualizado" (Fontinha, 1983:39). No se trata, sin embargo, de una "escritura" en el sentido de un sistema de signos directamente relacionados con el lenguaje verbal. Los sona cumplen diversas funciones; entre ellas, pero no obligatoriamente, la de signos mnemotécnicos que desencadenan la enunciación de una narrativa o de un adagio. El dibujo número 137 acompaña libremente la narración de un mito que explica el origen de un ritual secreto (ver Figura 2).

Samukimba y su esposa Namukimba tienen una hija, Nenga, que nació con la mano izquierda cerrada. Sorprendido por Namukimba, un genio gigante (mbongu o muyinde) que se estaba robando el maíz de la pareja, le revela que su hija esconde en su mano una serie de objetos que le permitirán presidir el rito de iniciación mungonge. No termina aquí el mito, pero la breve sinopsis de su inicio permite entender la relación que existe entre el dibujo y la narración. Una relación que podemos calificar de "paralelismo" o de "coordinación". Son los conceptos que Leroi-Gourhan usa para hablar de las protoescrituras paleolíticas que (todavía) no emprendieron el camino de la linearización fonética. Si adoptáramos la terminología del historiador francés, los sona serían "mitogramas", término que remite a un grafismo que no presenta, a diferencia de los pictogramas, "los estados sucesivos de una acción, sino a los personajes no estructurados linealmente que son los protagonistas de una operación mitológica" (Leroi-Gourhan, 1982:68). Los mitogramas revelan un pensamiento no lineal; representan "un modo de expresión en el cual el pensamiento dispone gráficamente de una organización en cierto sentido radiante"14 (Leroi-Gourhan, 1964:273). El grafismo chokwe es típico de las poblaciones bantúes del África centro-occidental. A raíz de la deportación de africanos de ese origen a lo largo del proceso de la 
trata esclavista, el grafismo bantú cruzó el Atlántico y sigue siendo usado en varias comunidades religiosas afroamericanas de tradición bantú, por ejemplo por los adeptos de la religión palo monte o mayombe en Cuba. ${ }^{15}$

Uno de los conjuntos iconográficos más ricos de las Américas es el que se encuentra en los textiles, la cerámica, la metalurgia y el propio suelo de la región Nasca-Paracas en la costa central del Perú. Las figuras que encontramos en estos diferentes soportes son más o menos comparables con los mitogramas ya mencionados: personajes multiformes, animales, plantas. Dominan, sin embargo, figuras de estatus claramente divino como el "Ser enmascarado" (Nasca) o el "Ser oculado" (Paracas). Podemos suponer que toda esta iconografía es básicamente mitográfica, pero nos topamos - como Humboldt ante los petroglifos del Casiquiare- con el problema de que desconocemos los mitos a los cuales alude; mitos orales que se desvanecieron sin duda mucho antes de la llegada de los españoles. También dejaron de practicarse los rituales vinculados directa o indirectamente a los grafismos textiles o cerámicos. Es poco, por lo tanto, lo que en este caso se puede decir sobre las relaciones entre grafismo, mito y rito. Particularmente sofisticadas, las figuras que pueblan los famosos mantos de Paracas-Necrópolis merecen, sin embargo, un comentario. En la Figura 3 aparece el personaje que Patrick Carmichael (2017) nombró el "Ser oculado" (ver Figura 3).

Lo primero que llama la atención si nos fijamos en una cualquiera de las representaciones del personaje es la posición de su cabeza. Carmichael, a este respecto, escribe lo que sigue:

La posición de cabeza invertida es sorprendente ya que le da una pausa al espectador en la búsqueda de la perspectiva (fig. 87, Paracas D). Si deseamos que el cuerpo esté en una posición anatómicamente vertical y comprensible volteamos la imagen, pero el resultado es que la cabeza está invertida. Si la cabeza está orientada hacia nosotros, estamos obligados a leer el cuerpo de manera inversa. ¿Aparece la criatura volando con el cuerpo dispuesto hacia atrás? Aquí se detecta una sensación de movimiento. Parece que el Ser Oculado se hubiese movido a gran velocidad desde arriba hacia abajo y, como un colibrí que hace una pausa en el aire, de repente dirige su rostro inclinado hacia atrás en dirección del observador con su cuerpo y apéndices emanando alrededor de él (Carmichael, 2017:161).

Lo que nos interesa aquí es que el "montaje" del personaje está destinado, si damos crédito a Carmichael, a producir la impresión de movimiento. En el manto RT-3233 del Museo Nacional de Arqueología, Antropología e Historia del Perú (Lima), un personaje análogo al que describe Carmichael va siendo repetido —o, más exactamente, variado - más de cincuenta veces entre la parte central y los bordes de la tela oriunda de ParacasNecrópolis (ver Figura 4).

En los bordes, ese personaje, colocado en posición horizontal, se repite diez veces en el eje izquierdaderecha; en el borde superior, su cabeza se halla a la derecha, en el borde inferior a la izquierda. Entre los dos bordes, el "movimiento", pues, se invierte. En la parte central, los ejes principales son las diagonales; nada impide, sin embargo, leer el movimiento variacional del personaje según un eje horizontal o vertical. Si leemos el conjunto en términos horizontales o verticales, el personaje aparecerá, alternativamente, con los pies hacia abajo o hacia arriba. Lo verdaderamente espectacular de este y de otros mantos análogos no es, sin embargo, su geometría, sino la variación del personaje a partir del cambio de color que van sufriendo los diferentes elementos que lo componen. Analizando un manto análogo, Franz Boas (1955:47-48) intentó sistematizar los cambios de color enfocando tan solo el rostro, el vestido y las piernas del personaje. Su análisis le permitió descubrir una estructura de tipo rítmico relativamente sencilla. Si se analizaran los cambios colorimétricos de los aproximadamente treinta elementos que componen al personaje de nuestro manto, también encontraríamos una estructura rítmica, pero esta resultaría mucho más compleja que la que descubrió Boas. Dejando este ejercicio para otra oportunidad, nos interesa enfatizar la presencia múltiple del "cine(ma)" — kív $\mu \alpha$ (kínema), en griego, significa movimiento- que hay en este y otros mantos análogos. Sugieren ese movimiento el 
montaje de cada uno de los avatares del personaje, el montaje geométrico de sus apariciones en la tela, el montaje colorimétrico de cada avatar y el del conjunto de sus apariciones. Si nuestra lectura pasa rápidamente de una figura a otra y a otras más, el personaje empezará a moverse por el muy sofisticado juego de los colores, la posición respectiva de sus pies y su cabeza y su colocación en el "cuadro". Lo que refuerza todavía la impresión de cercanía con el cine es - para nosotros, nacidos después de 1895 - la "película" que aparentan representar los bordes del manto.

La sociedad que produjo las telas de Paracas no conocía la escritura (en el sentido de tecnología para la fijación del discurso verbal), pero inventó un tipo de grafismo que prefigura, en varios de sus aspectos, el "cine". El cine, típico producto de la modernidad industrial, surge en tanto nuevo "lenguaje" en un mundo en el cual (pre)domina, en términos de comunicación, el discurso verbal escrito. Pero, como lo señaló Edgar Morin en Le cinéma ou l'homme imaginaire (1956), muchos de quienes, en las primeras décadas del siglo XX, comentan la impresión que el cine produce en la mente de los espectadores, hablan de las proyecciones cinematográficas como de un descenso a un mundo arcaico, mágico, de sueño: a ese mundo que era el de las tradiciones orales. Además, en sus primeras décadas, el cine, en particular el cine de vanguardia y, especialmente, el de tendencia surrealista, se halla sin duda más cerca de la mitografía (en el sentido de Leroi-Gourhan) que del discurso racional que auspicia la escritura.

Otro ejemplo. Elllamado lienzo de Quauhquecholan, una pintura mexicana de dimensiones considerables (235 x 325 centímetros), representa, según las investigaciones de Florine Asselbergs (2002), la conquista española de Guatemala (ver Figura 5).

Esta obra, pintada por artistas oriundos de Quauhquecholan (hoy San Martín Huaquechula, Puebla, México), enfatiza la participación de un contingente nutrido de quauhquecholtecas en esa conquista. El documento muestra decenas de escenas pictográficas que forman parte de una narrativa histórica sobre el proceso mencionado; una narrativa que necesita, para poder ser entendida por el espectador, de un comenta- rio oral, más o menos como el retablo de Maese Pedro en el Quijote de Cervantes. A diferencia de un texto escrito, a diferencia también de la mayoría de los textos pictográficos, esta pintura — que ofrece una narrativa histórica - no puede ser leída a partir de una lógica lineal. Las diferentes escenas están distribuidas en el espacio. El lienzo, de hecho, es un mapa, semejante a los "mapas" mesoamericanos prehispánicos. Las escenas se ubican en el lugar que les corresponde en términos de la geografía aludida. Solo puede recitar la narrativa quien conoce su cronología.

\section{Aparición de la escritura}

La escritura propiamente dicha nació, según LeroiGourhan, "del complemento de dos sistemas: el de los 'mitogramas' y el de la linearización fonética” (LeroiGourhan 1964:283). Un códice mexicano de estilo prehispánico como el que se conoce bajo el título de Tira de la peregrinación permite hacerse una idea de cómo puede estar naciendo, confusamente, una escritura. Este códice evoca la "peregrinación" de los aztecas desde Aztlán, su mítico lugar de origen, hasta Tenochtitlan. Los participantes de esta epopeya se nombran mediante glifos onomásticos convencionales; el año en que ocurre tal suceso se indica con los glifos convencionales correspondientes. El progreso de la peregrinación, en cambio, se evoca con medios pictográficos (ver Figura 6). ${ }^{16}$

A diferencia del documento anterior, la Tira sí sigue la lógica lineal que es la de la escritura propiamente dicha. Pero las peripecias del viaje no constan realmente en la Tira; ellas se encuentran — con todos los detalles pertinentes - en el discurso narrativo oral cuya transcripción en náhuatl fue descubierta por Patrick Johansson (2004) en otro documento, el Códice Aubin. Con la Tira estamos, pues, en un momento de transición entre, por un lado, un sistema oral combinado con un grafismo multidimensionaly, por otro, la emancipación del grafismo y su transformación en escritura propiamente dicha. Desde el punto de vista de la manera de pensar, se trata de la transición entre una mentalidad mítica y otra histórica. Con la invasión española y las transformaciones radicales del sistema económico- 
político, cultural y religioso impuestas por los intrusos, esta transición quedó trunca.

En su obra Las transformaciones del hombre, Lewis Mumford escribe lo que sigue: "El hombre, cuando no era todavía sino un simple recolector y ni siquiera un cazador bien armado, ya había sin duda inventado la mayor parte de los instrumentos decisivos de la cultura" ([1956]2008:33-34). Mumford se refiere sin duda al lenguaje verbal y al grafismo, al gesto y al rito, al juego - ya estudiado por Huizinga (1972) en su Homoludens-. Además de estos instrumentos decisivos de la cultura, el hombre ya había adquirido la facultad de soñar, de rememorar y narrar el pasado, de analizar el presente, de imaginar el futuro, de imaginar otros mundos. Ese hombre de los comienzos va desarrollando un tipo de pensamiento especulativo que posee su peculiar racionalidad, ese pensamiento que Claude Lévi-Strauss calificó de "salvaje" o "mágico"; un pensamiento que:

[...] no es un inicio, un comienzo, un esbozo, la parte de un todo todavía no realizado, sino que forma un sistema bien articulado, independiente [...] de ese otro sistema que constituirá la ciencia, a no ser por la analogía formal que los aproxima y que hace del primero una especie de expresión metafórica del segundo" (Lévi-Strauss, 1962:21).

Todo este sistema cultural se va desarrollando durante milenios, casi siempre sin el auxilio de una escritura destinada a almacenar cabalmente los diferentes discursos verbales que se van gestando.

Las escrituras capaces de fijar plenamente el lenguaje verbal no surgirán sino en pocos lugares del planeta, pero terminarán difundiéndose a escala regional o, en el caso del alfabeto, en todos los territorios alcanzados por el expansionismo europeo. Contrariamente a lo que dan a entender muchos estudios, la escritura no toma el lugar de la más-que-oralidad, no la borra, sino que reestructura — desde una posición hegemónica — toda la esfera de la comunicación, reorientando al mismo tiempo la producción y la difusión del conocimiento. Con la irrupción de la escritura y las artes de élite que la acompañan (pintura al óleo, música polifónica, ballet, etcétera), los arcaicos plurisistemas de comunicación no desaparecen, pero sí quedan relegados, hasta la aparición de los nuevos medios de comunicación (foto, cine, radio, disco, etcétera) y las vanguardias artísticas, a un papel social y políticamente marginal. La cosmovisión básicamente mítica que caracteriza esos sistemas arcaicos sigue viva pero atrofiada en el seno de ciertos sectores subalternos o periféricos de las sociedades con escritura. Con la crisis de la modernidad europea que se produce desde fines del siglo XIX y que se acentúa con la Primera Guerra Mundial, el pensamiento no racional, no lineal o no teleológico vuelve a atraer la atención de quienes —antropólogos, historiadores, psicólogosestudian la cultura de las poblaciones más periféricas o el psiquismo humano en general. Paralelamente, ese pensamiento premoderno manifiesta su presencia en varias corrientes del arte de vanguardia. Esto explica por qué podemos construir puentes entre las narrativas del inconsciente (Freud) y los mitos antiguos o entre la pintura de vanguardia - véase, por ejemplo, Les vierges du pharaon de Louis Soutter, de los años 1935-1940 (ver Figura 7) - y el arte rupestre.

Puentes que también se pueden tender entre el

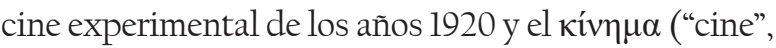
"movimiento") premoderno de los tejidos de Paracas, o todavía entre la danza "moderna" y los rituales arcaicos (piénsese, por ejemplo, en el ballet vanguardista de inspiración africana La création du monde de 1923, compuesto por Blaise Cendrars (libreto), Darius Milhaud (música) y Fernand Léger (pintura y máscaras).

Todo lo que precede sugiere que limitar el estudio de la "oralidad" — o, más exactamente, del plurisistema comunicativo previo a la aparición y la difusión global de la escritura- a la relación entre la producción verbal oral y la producción verbal escrita lleva a subestimar la complejidad y la riqueza de los sistemas no letrados y a ver en la escritura el fin último —el telos - de los procesos que se han venido dando en la esfera de la comunicación humana. La escritura, no se trata de negarlo, ha tenido una importancia capital para el advenimiento y el ascenso de la modernidad occidental. Pero no acabó con el sistema arcaico, en rigor un plurisistema que constituye un horizonte amplio y de larguísima 
trayectoria en el que caben — sincrónica o diacrónicamente- no solo la oralidad (cualquier oralidad) y la escritura (cualquier escritura), sino todos los sistemas de comunicación creados por el hombre.

\section{Notas}

${ }^{1}$ Los pacaás novos (o wari') fueron entrevistos por el famoso "sertanista" Rondon en la cabecera del río de ese nombre, en la frontera con Bolivia, en el actual municipio de Guajará-Mirim, Rondônia occidental, Brasil. Los pacaás novos se encuentran, pues, lejos del itinerario seguido por Mário de Andrade en su viaje amazónico. A fines de los años 1920, cuando Andrade, el "turista aprendiz", los inventó, la fama de los pacaás novos debe de haber sido la de salvajes antropófagos. Recién a mediados del siglo XX se institucionalizaron sus contactos con "Brasil" (Philips, 2015).

${ }^{2}$ Salvo indicación contraria, todas las traducciones han sido realizadas por el autor de este trabajo.

${ }^{3}$ Cuando una cita, por su terminología, su fraseología u otras características lo hace deseable, ofreceremos a pie de página el texto original. A continuación incluimos el texto original de Rousseau de esta cita: “[...] L'écriture, qui semble devoir fixer la langue, est précisément ce qui l'altère; elle n'en change pas les mots, mais le génie; elle substitue l'exactitude à l'expression. L'on rend ses sentiments quand on parle, et ses idées quand on écrit. En écrivant, on est forcé de prendre tous les mots dans l'acception commune; mais celui qui parle varie les acceptions par les tons, il les détermine comme il lui plaît; moins gêné pour être clair, il donne plus à la force; et il n'est pas possible qu'une langue qu'on écrit garde longtemps la vivacité de celle qui n'est que parlée".

4 "[...] si nous n'avions jamais eu que des besoins physiques, nous aurions fort bien pu ne parler jamais, et nous entendre parfaitement par la seule langue du geste".

5 "Les moyens généraux par lesquels nous pouvons agir sur les sens d'autrui se bornent à deux, savoir, le mouvement et la voix. L'action du mouvement est immédiate par le toucher ou médiate par le geste: la première, ayant pour terme la longueur du bras, ne peut se transmettre à distance: mais l'autre atteint aussi loin que le rayon visuel. Ainsi restent seulement la vue et l'ouie pour organes passifs du langage entre des hommes dispersés. Quoique la langue du geste et celle de la voix soient également naturelles, toutefois la première est plus facile et dépend moins des conventions: car plus d'objets frappent nos yeux que nos oreilles, et les figures ont plus de variété que les sons; elles sont aussi plus expressives et disent plus en moins de temps".

6 "Facteur, dans le Commerce, est un agent qui fait les affaires \& qui négocie pour un marchand par commission: on l'appelle aussi commissionnaire; dans certains cas, courtier; \& dans l'Orient, coagis, commis" (Diderot y d'Alembert, 1751-1772).

7 “[...] les facteurs se prenant la main l'un à l'autre, et modifiant leurs attouchements d'une manière que personne ne peut apercevoir, traitent ainsi publiquement, mais en secret, toutes leurs affaires sans s'être dit un seul mot".

${ }^{8}$ Rito originalmente descrito por Alice Cunningham Fletcher. Lo menciona Claude Lévi-Strauss en La pensée sauvage (1962:17).

9 “[...] la technicité à deux pôles de nombreux vertébrés aboutissait chez les Anthropiens à la formation de deux couples fonctionnels (main-outil et face-langage), faisant intervenir au premier rang la motricité de la main et de la face dans le modelage de la pensée en instruments d'action matérielle et en symboles sonores. L'émergence du symbole graphique à la fin du règne des Paléanthropes suppose l'établissement de rapports nouveaux entre les deux pôles opératoires, rapports exclusivement caractéristiques de l'humanité au sens étroit du terme, c'est-à-dire répondant à une pensée symbolisante, dans le mesure où nous en usons nous même".

${ }^{10} \mathrm{El}$ mismo pensamiento manual sigue existiendo hasta hoy. En la provincia de Canas (departamento del Cusco), cuatro comunidades se reúnen anualmente para reconstruir el Q'iswachaka, un puente colgante sobre el río Apurímac muy semejante al que describe Betanzos hacia 1550.

11 "Au piétinement qui constitue le cadre rythmique de la marche, s'ajoute donc chez l'homme l'animation rythmique du bras; alors que le premier régit l'intégration spatio-temporelle et se trouve à 
la source de l'animation dans le domaine social, le mouvement rythmique du bras ouvre une autre issue, celle d'une intégration de l'individu dans un dispositif créateur non plus d'espace et de temps, mais de formes. La rythmicité du pas a finalement abouti au kilomètre et à l'heure, la rythmicité manuelle a conduit vers la capture et l'immobilisation des volumes, source d'une réanimation purement humaine".

${ }^{12}$ Los hallazgos más recientes (Indonesia) hablan de grafismos realizados hace más de 40000 años (Domínguez, 2019).

${ }^{13}$ Con esta afirmación, Boas concluye un pasaje dedicado a las relaciones que hay entre la expresión literaria primitiva y ciertas actividades motoras: "Primitive literary expression is often, though not by any means always, accompanied by some kind of motor activity; or certain kind of motions may release articulations that take the form of song or of spoken words. Strong, but controlled emotion finds utterance in movements of the body and in articulation, and emotional speech releases similar movements. This may been inferred from the frequent association of song and dance, of song and games, and that of gestures and lively speech" (Boas, 1955:303).

${ }^{14}$ Una definición que se podría aplicar a parte de la pintura cubista.

${ }^{15}$ En su bien documentado libro, Escritura gráfica kongo y otras narrativas del signo, el estudioso cubano Bárbaro Martínez Ruiz (2012) califica ese grafismo de "escritura". Si reservamos este término -como lo estoy haciendo en este trabajo- a los sistemas gráficos directamente vinculados a un discurso verbal, el grafismo chokwe o el de los practicantes de palo monte no puede ser calificado de "escritura".

${ }^{16}$ A veces confundido con el mitograma, el pictograma "es una figura o una secuencia de figuras que describen concretamente una acción. Lo que caracteriza el pictograma en relación con la escritura es su linearidad" (Leroi-Gourhan, 1982:67).

\section{Referencias}

Andrade, Mário de (1983). O turista aprendiz. São Paulo: Livraria Duas Cidades.
Asselbergs, Florine (2002). "La conquista de Guatemala: nuevas perspectivas del lienzo de Quauhquecholan en Puebla”. En Mesoamérica, 23(44), 1-53.

Betanzos, Juan de (2015). "Suma y narración de los Incas". En Rodolfo Cerrón-Palomino y Francisco Hernández Astete (eds.), Juan de Betanzos y el Tahuantinsuyo. Nueva edición de la Suma y narración de los Incas. Lima: PUCP, 107-440.

Boas, Franz (1955). Primitive art. Nueva York: Dover Publications.

Carmichael, Patrick (2017). "Evidencia iconográfica de la génesis Nasca”. En Cecilia Pardo y Peter Fux (ed.), Nasca. Lima y Zúrich: Asociación Museo de Arte de Lima, Museo Rietberg.

Diderot, Denis y Jean le Rond d'Alembert (1751-1772). Encyclopédie ou Dictionnaire raisonné des Sciences, des Arts et des Métiers. The ARTFL Encyclopédie. Chicago: Universidad de Chicago. Disponible en https:/encyclopedie.uchicago.edu/

Domínguez, Nuño (2019). "Descubierta la obra de arte más antigua". En El País, 11 de diciembre. Disponible en https:/elpais.com/elpais/2019/12/11/ciencia/1576085162_065582.html

Fontinha, Mário (1983). Desenhos na areia dos quiocos do nordeste de Angola. Lisboa: Instituto de Investigação Científica Tropical.

Huizinga, Johan (1972). Homo ludens. Madrid: Alianza Editorial.

Humboldt, Alejandro de (1991). Viaje a las regiones equinocciales del nuevo continente. Caracas: Monte Ávila.

Johansson, Patrick (2004). La palabra, la imagen y el manuscrito. Lecturas indígenas de un texto pictórico en el siglo XVI. México: UNAM.

Leroi-Gourhan, André (1964). Le geste et la parole I. Technique et langage. París: Albin Michel.

Leroi-Gourhan, André (1965). Le geste et la parole II. La mémoire et les rythmes. París: Albin Michel.

Leroi-Gourhan, André (1982). Les racines du monde: entretiens. París: Belfond.

Lévi-Strauss, Claude (1962). La pensée sauvage. París: Plon. Martínez-Ruiz, Bárbaro (2012). Escritura gráfica kongo y otras narrativas del signo. México: El Colegio de México. Moisseeff, Monika (1988-1989). "Représentations non- 
figuratives et singularité individuelle: les churinga de désert central australien". En Louis Perrois y ClaudeFrançois Baudez (coords.), Anthropologie de l'art: formes et significations (Arts de l'Afrique, de l'Amérique et du Pacifique). París: Université de Paris 1 Panthéeon-Sorbonne, fascículo II, pp. 171-189.

Morin, Edgar (1956). Le cinéma ou l'homme imaginaire. Essai d'anthropologie. París: Minuit.

Mumford, Lewis ([1956]2008). Les transformations de l'homme. París: Editions de l'Encyclpédie des Nuisances. Pardo, Cecilia y Peter Fux (eds.) (2017). Nasca. Lima y Zúrich:
Asociación Museo de Arte de Lima, Museo Rietberg. Philips, David J. (2015). "Pakaás Novos-Wari”. En Indígenas do Brasil. Os primeiros povos do Brasil, 12 de enero. Disponible en https://brasil.antropos.org.uk/223-pakaas-novos/ Rousseau, Jean-Jacques ([1782]2012). "Essai sur l'origine des langues". En Collection complète des auvres, Genève, 1780-1789, vol. VIII. Disponible en www.rousseauonline.ch

Severi, Carlo (2004). Il percorso e la voce. Un'antropologia della memoria. Turín: Einaudi.

Figura 1. Ejemplos más antiguos de simbolismo gráfico

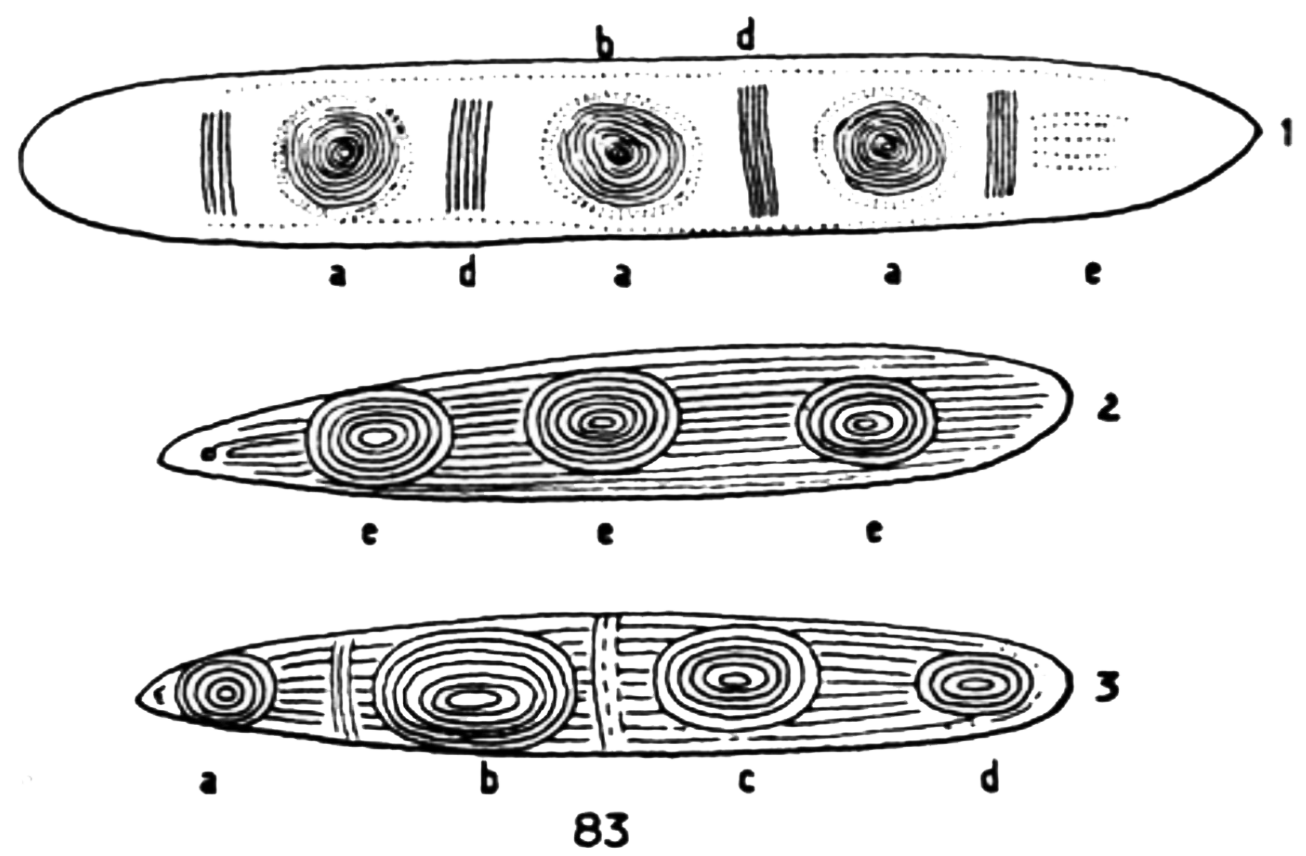

Fuente: tomado de Leroi-Gourhan (1964:264). 
Figura 2. Dibujo número 137

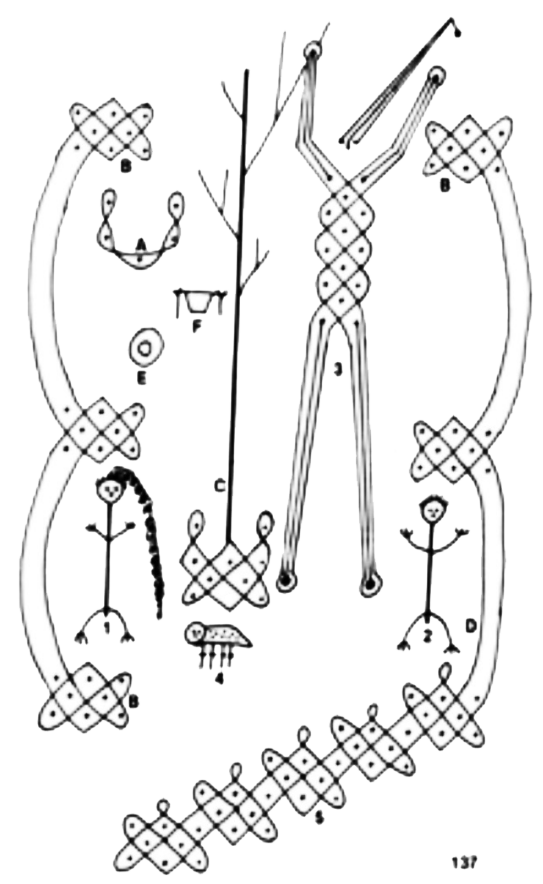

Fuente: Fontinha (1983).

Figura 3. Ser oculado

D

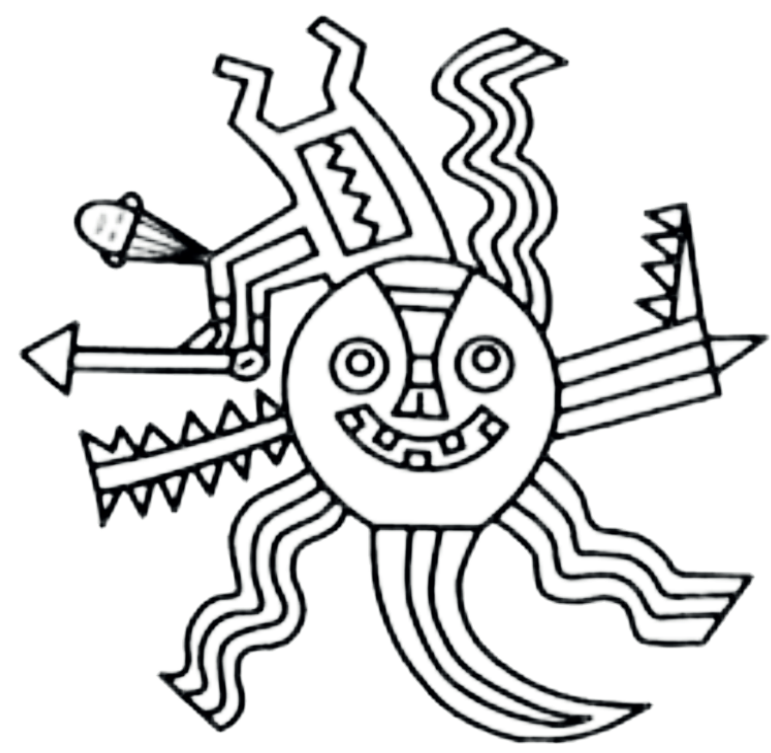

Fuente: Patrick Carmichael (2017). 
Figura 4. Fragmento del manto RT-3233 de Museo Nacional de Arqueología, Antropología e Historia del Perú (Lima)

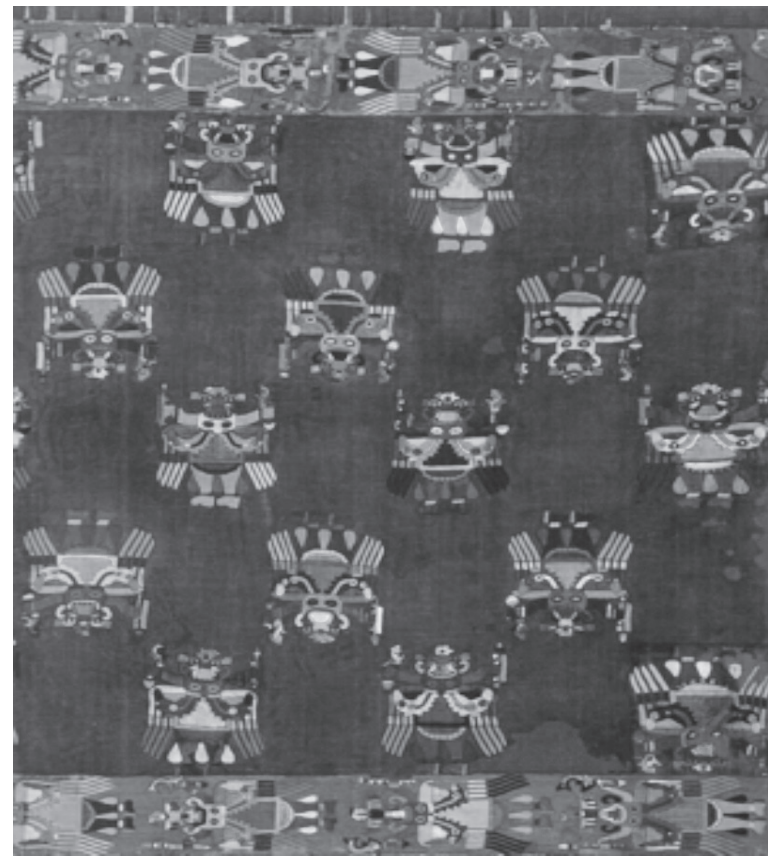

Fuente: reproducido en Pardo y Fux (2017).

Figura 5. La conquista de Atitlán (fragmento del lienzo de Quauhquecholan.

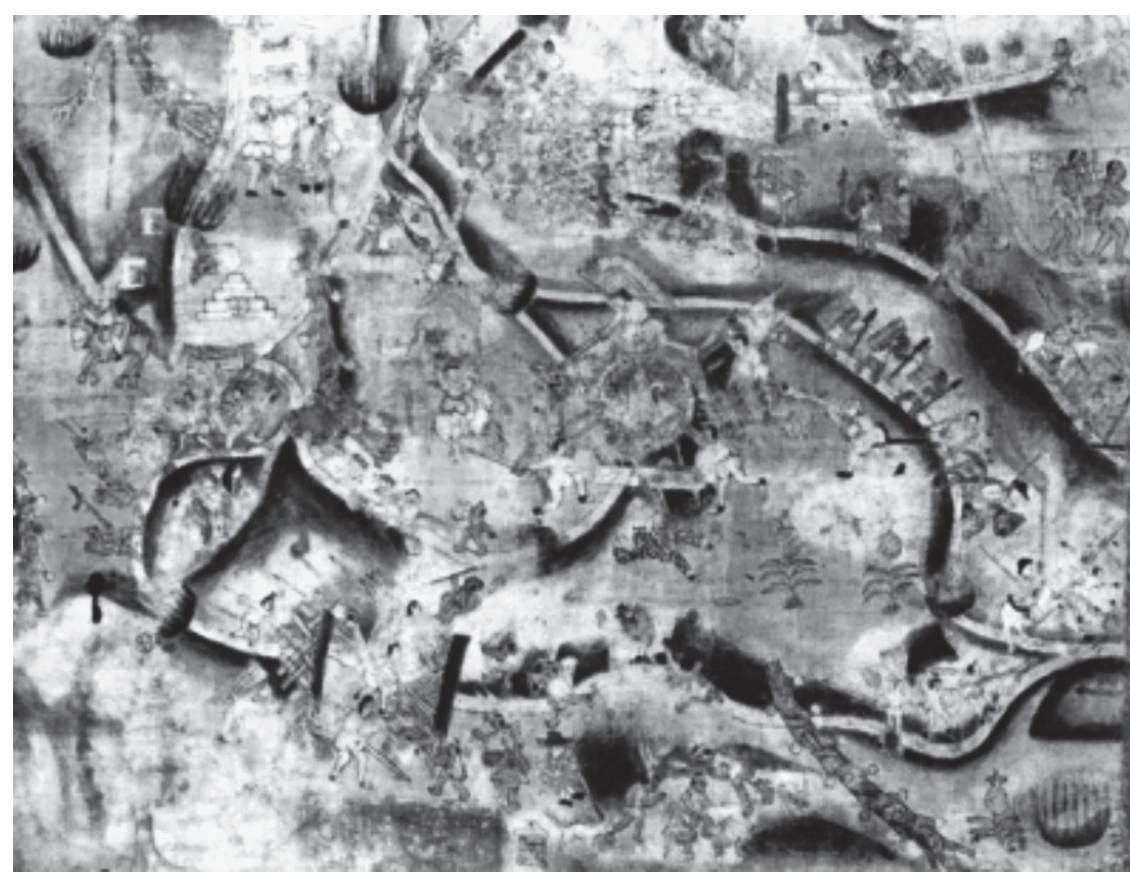

Fuente: Asselbergs (2002). 
Figura 6. Aztlán: Mixcóatl y Chimalma a los pies del templo de Amímitl

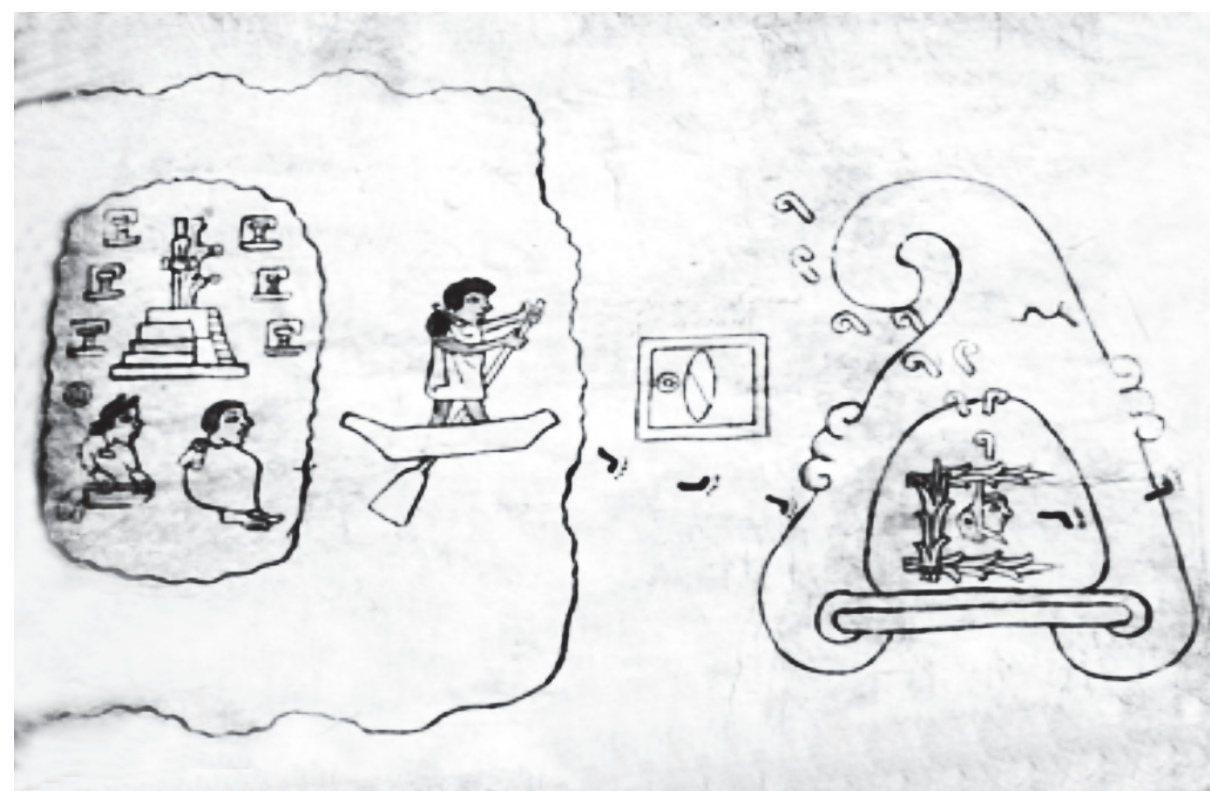

Fuente: Tira de la peregrinación, f. 1.

Figura 7. Louis Soutter, “Les vierges du pharaon” (1935-1940)

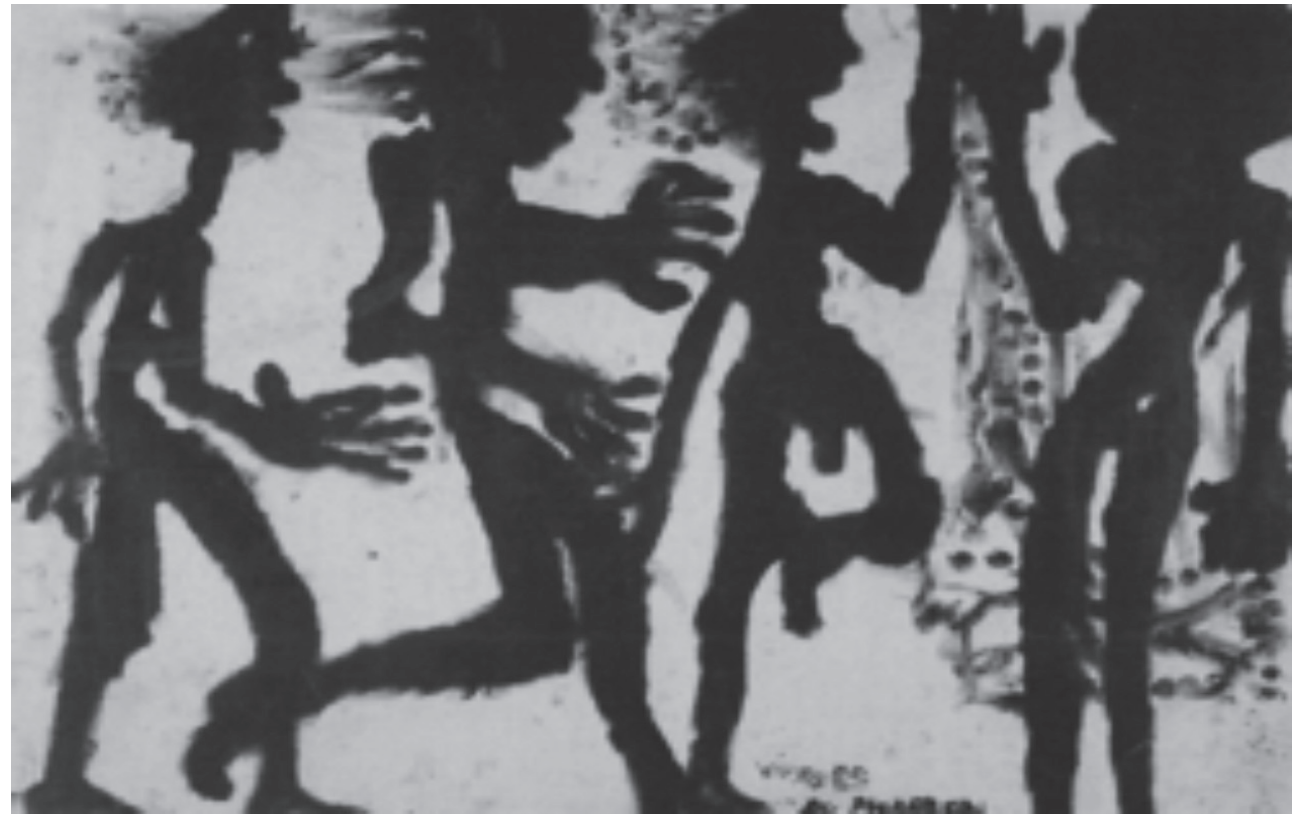

Fuente: https://www.wikiart.org/es/louis-soutter 
Figura 8. La création du monde, ballet creado por Blaise Cendrars, Darius Milhaud y Fernand Léger

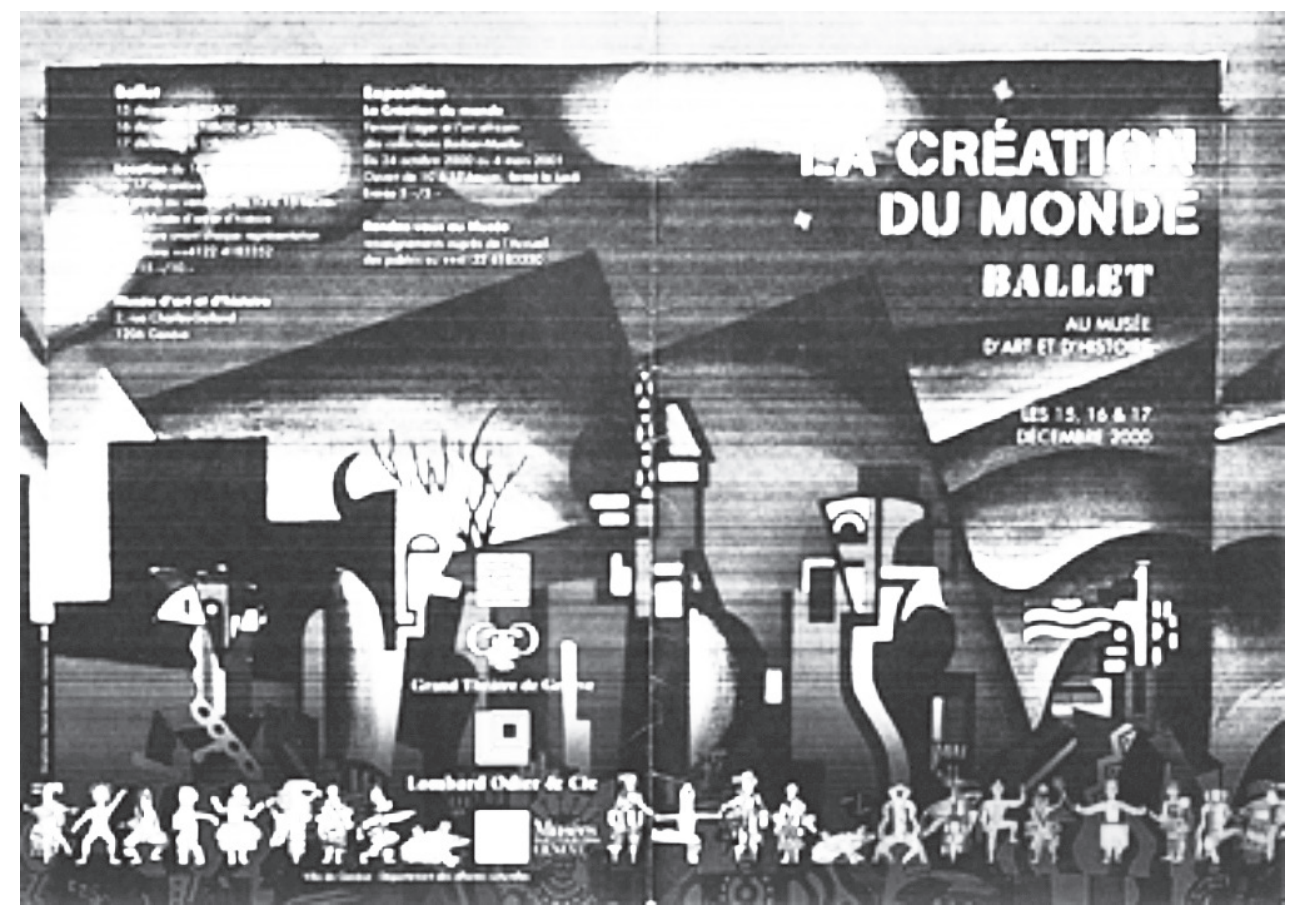

Fuente: http://www.fluxlaboratory.com/media/document/0/dossier-de-presse-la-creation-du-monde-fr-l.pdf 